\title{
Collaborating on a creative solution to teach creativity to Business students
}

\section{Dewa Wardak}

University of Sydney, Australia

\author{
Abdul Razeed \\ University of Sydney, Australia \\ Jane Thogersen \\ University of Sydney, Australia \\ Eve Guerry \\ University of Sydney, Australia
}

Keywords: creativity; analytics; business; museum; object-based learning; Covid-19.

\section{The challenge}

We are sharing our experience of co-designing a large new core unit of study for a Master of Commerce program at an Australian university, and the challenges introduced by the Covid-19 pandemic. The unit was designed to teach postgraduate Business students about creativity and analytics and to emphasise that both mindsets are complementary and necessary graduate attributes. Students often think that a creative mindset means you must be born creative. There is also a myth that creative people are not analytical, but the truth is that creativity is enhanced, guided, and validated by data and analytics (Gibbons, 2019). There is constant dynamic movement between what one sees in the data and how the data reframes creativity. Our main challenge was dealing with Covid-19 restrictions and designing a blended solution as more than $70 \%$ of our students were enrolled remotely due to the closure of the borders between Australia and other countries. More than 2000 students were enrolled on this unit in Semester One, 2021, and this added to the complexity of how to offer a connected experience at scale to students learning remotely. 


\section{The response}

We define creativity as both novel and useful (Stein, 1953; Barron, 1955). Our aim was to emphasise that creativity is not just in the students' minds and that their material environment and creative practices are important for developing creative solutions in business. The Educational Developer (first author) co-designing this unit sought a creative solution to teach students about creativity in business and thus instigated collaboration with the on-campus Chau Chak Wing Museum to design an Object-Based-Learning (OBL) workshop for students. OBL is a student-centred approach which aids the acquisition of subject specific skills, cross-disciplinary knowledge, practical observational, and other transferable skills (Chatterjee and Hannan, 2016). The Unit Coordinator (second author) handled the design and logistical aspects, including training teaching staff, and led the collaboration with the two Academic Engagement Curators at the museum (the third and fourth authors). This was a new and innovative way to teach business students about creativity and a first collaboration between the Business School at the University of Sydney and a museum. The collaboration with the museum offered a novel opportunity to activate creativity through interaction with the objects around us.

The solution involved designing an OBL workshop for the students at the museum. Our blended format included six two-hour tutorial classes for the onsite face-to-face students and 53 tutorial classes for remote online students. The face-to-face and online students did not attend any synchronous classes together. OBL involves deep observation and multi-sensory engagement with physical objects, so the scalability and the blended delivery format provided a particular challenge. To manage the scale, the face-to-face students only visited the museum for half their tutorial time (one hour) and the remote students engaged in digital OBL. Digital objects were pre-selected and links to the online catalogue and 3D digital models were provided for the students to access during the tutorials. Although engaging with physical objects is different to engaging with digital objects, both offer opportunities for learning. Engaging in digital OBL has certain benefits, for example digital objects have links to contextual information, which can stimulate thinking on related topics, offer the potential for collaboration of larger numbers of students with the same objects in real time (Frost, 2009), and it allows the close inspection of objects for which size, state of preservation, and/or toxicity could make them otherwise inaccessible (McLaughlin et al., 2000). In some cases, the digital objects provide an entirely different experience, such as engaging with 3D objects as digital models. 
The museum's Academic Engagement Curators designed and ran the OBL activities with the onsite students in the museum learning studios. They also designed activities to engage the remote students in OBL using the museum's digital objects catalogue. As the remote classes were delivered by the unit coordinators and tutors, training was provided to introduce the teaching team to $\mathrm{OBL}$ and $\mathrm{OBL}$-delivery online. The facilitators began the session with short and fun activities designed to activate deep looking and communication across boundaries. Working in small groups, students were then presented with five seemingly disconnected artworks, artefacts and specimens; for example, an early twentieth-century slide-rule, an abstract painting, a Massim Ancestor Figure, a bronze thumb from an Ancient Greek life-size statue, and an Eastern Brown Snake specimen collected in the mid-nineteenth century. Utilising their powers of observational analysis and creativity, students worked collaboratively to develop a narrative that connected the objects in an unexpected and engaging way. Each group then presented their creative output to the class. In the debrief at the end of the session, students were encouraged to reflect upon their process and how the activity acted as a meeting point for analytical and creative approaches.

\section{Recommendations}

Although creative and analytical mindsets are often perceived as opposing, taking a multidisciplinary approach to curriculum design can foster smoother integration between the two mindsets. Our blended learning approach to the design of this workshop allowed students to engage in OBL activities regardless of their onsite or offsite enrolment modes (Teo, Kim and Jiang, 2020). When designing innovative blended activities, particularly under the constraints of the pandemic, thorough consideration of multiple aspects is important, including student learning and engagement, logistics, technology implementation, and clear communication between all stakeholders (Zhang and Dang, 2020). Careful thought in instructional design has been shown to be an important determinant of student success, perceived usefulness of the activities, and ease of use (Liu et al., 2010).

Museum curatorial work is a highly analytical and creative process, and this particular museum is a case study in interdisciplinarity. Here, different disciplines collide to explore 
challenging and creative ideas through art, objects, and specimens spanning thousands of years and covering areas and cultures across the globe. Incorporating a museum $\mathrm{OBL}$ experience acted as a disruptor for students, initially placing them in unfamiliar territory and removing the standard support structures that they find in a traditional accounting classroom. The OBL activities encouraged students to see the value in different experiences and perspectives (teamwork) and prompted discussion among their peers to form well-rounded and creative output.

OBL as a pedagogy is particularly effective for group work and skill development in empathy, communication, observation, analysis, deductive reasoning, problem solving, and creative and critical thinking; all wonderfully transferrable skills for future employment. Objects, whether strange or familiar, 'have the power to inspire, inform, excite and educate' (Chatterjee, 2010, p.181), and we aim to strengthen the online OBL experience to ensure that this is as meaningful and impactful as the on-campus sessions. Access to a virtual museum tour, an expanded collection of digital 3D models and better access to high resolution imaging will improve the online OBL learning experience for future cohorts.

\section{References}

Barron, F. (1955) 'The disposition toward originality', The Journal of Abnormal and Social Psychology, 51, pp.478-485. http://doi.org/10.1037/h0048073.

Chatterjee, H. J. (2010) 'Object-based learning in higher education: the pedagogical power of museums', Putting University Collections to Work in Teaching and Research Proceedings of the 9th Conference of the International Committee of ICOM for University Museums and Collections (UMAC). Berkeley, USA 10-13 September, pp.179-182. Available at:

https://edoc.hu-berlin.de/bitstream/handle/18452/9349/chatterjee.pdf (Accessed: 5 May, 2021)

Chatterjee, H. J. and Hannan, L. (eds.) (2016) Engaging the senses: object-based learning in higher education. New York: Taylor and Francis. 
Frost, O. C. (2009) 'When the object is digital: properties of digital surrogate objects and implications for learning', in R. Parry (ed.) Museums in a digital age. $1^{\text {st }}$ edn. Abingdon: Routledge, pp.72-85.

Gibbons, S. (2019) 'Why you can't choose between creativity and data', Forbes, 9 May. Available at: https:/www.forbes.com/sites/serenitygibbons/2019/05/09/why-youcant-choose-between-creativity-and-data/?sh=5341d955291c (Accessed: 7 May 2021).

Liu, Y., Li, H. and Carlsson, C. (2010), 'Factors driving the adoption of m-learning: an empirical study', Computers \& Education, 55(3), pp.1211-1219. https://doi.org/10.1016/j.compedu.2010.05.018.

McLaughlin, M. L., Sukhatme, G., Shahabi, C., Hespanha, J., Ortega, A. and Medioni, G. (2000) 'The haptic museum', in Conference Proceedings EVA 2000: Electronic Imaging \& the Visual Arts. Florence, Italy 27-31 March. Available at: https://infolab.usc.edu/DocsDemos/eva2000.pdf (Accessed: 5 May 2021).

Stein, M. I. (1953) 'Creativity and culture', The Journal of Psychology: Interdisciplinary and Applied, 36, pp.311-322. http://doi.org/10.1080/00223980.1953.9712897.

Teo, T. S. H., Kim, S. L. and Jiang, L. (2020) 'E-learning implementation in South Korea: Integrating effective-ness and legitimacy perspectives', Information Systems Frontiers, 22, pp.511-528. https://doi.org/10.1007/s10796-018-9874-3.

Zhang, Y. G. and Dang, M. Y. (2020) 'Understanding essential factors in influencing technology-supported learning: a model toward blended learning success', Journal of Information Technology Education: Research, 19, pp.489-510. https://doi.org/10.28945/4597.

\section{Author details}

Dewa Wardak is a Lecturer in Educational Development at the University of Sydney Business School. She is a Fellow of the Higher Education Academy (FHEA). With a 
background in Learning Sciences, Dewa's interests include educational development for academics, research in networked learning, multimodal approaches to the analysis of learning and teaching environments, and research supervision and mentoring.

Abdul Razeed is a Lecturer in the Discipline of Accounting at the University of Sydney Business School. Abdul has co-authored two academic books and a case study. He teaches across both the undergraduate and postgraduate programs. His passion lies in developing and continually innovating in large core units. Abdul has been nominated several times for the Wayne Lonergan Teaching Award has also consistently won awards for tutoring at the University of Sydney Business School.

Jane Thogersen is Academic Engagement Curator at the University of Sydney's Chau Chak Wing Museum. She has a background in Museology, especially historical and cultural material, and has extensive experience in activating collections for life-long learning. She is particularly interested in utilising diverse collections to form unexpected and enriching connections for learning, teaching and research.

Eve Guerry is Academic Engagement Curator at the University of Sydney's Chau Chak Wing Museum. Eve has a background in Archaeology, Egyptology and Museum Education. She has been designing and implementing curriculum-linked Object-Based Learning programs into teaching and research for over fifteen years, including strategies for multi-modal interdisciplinary engagement with museum collections. 